\title{
METHODOLOGICAL CHALLENGES FOR COLLABORATIVE LEARNING RESEARCH
}

This is a post-print of an article submitted for consideration in the Learning and Instruction (C) 2007 Elsevier.

Personal use of this manuscript is permitted. Permission from Elsevier must be obtained for any other commercial purpose.

This article may not exactly replicate the published version, due to editorial changes and/or formatting and corrections during the final stage of publication. Interested readers are advised to consult the published version which can be found at:

http://www.sciencedirect.com/science/article/pii/S0959475207000503

doi: $\{10.1016 /$ j.learninstruc.2007.03.004\}

Please refer this manuscript as:

Strijbos, J. W., \& Fischer, F. (2007). Methodological challenges for collaborative learning research. Learning and Instruction, 17(4), 389-393. 
Running head: Methodological challenges for collaborative learning research

Methodological challenges for collaborative learning research

\author{
Jan-Willem Strijbos ${ }^{1}$ \\ Leiden University
}

Frank Fischer

Ludwig Maximilians-University München

Cite as: Strijbos, J. W., \& Fischer, F. (2007). Methodological challenges for collaborative learning research. Learning \& Instruction, 17, 389-393.

\footnotetext{
${ }^{1}$ Correspondence can be sent to Jan-Willem Strijbos, Leiden University, Faculty of Social and Behavioural Sciences, Centre for the Study of Learning and Instruction, P. O. Box 9555, 2300 RB, Leiden, The Netherlands. E-mail: jwstrijbos@fsw.leidenuniv.nl
} 


\begin{abstract}
Research on collaborative learning, both face-to-face and computer-supported, has thrived in the past 10 years. The studies range from outcome-oriented (individual and group learning) to process-oriented (impact of interaction on learning processes, motivation and organisation of collaboration) to mixed studies. Collaborative learning research is multi-disciplinary. This introduces a multitude of theoretical accounts for collaborative learning, accompanied by a broad spectrum of methods to study processes and outcomes of collaboration. This special issue will provide an overview of methods that are at the core of current research effort, but also identifies opportunities and problems to sensibly combine methods into mixed method approaches.
\end{abstract}

Keywords: Collaborative learning; Cooperative Learning; Computer-Supported Collaborative Learning (CSCL); Methodology; Description standards; Process Analyses 
Collaborative learning is a multidisciplinary field in the learning sciences encompassing researchers with backgrounds in psychology, educational science, sociology, anthropology, communication science, and computer science. Each discipline has a specific theoretical perspective on 'collaborative learning' and specific methods to study it.

The variation in theoretical perspectives on collaborative learning is reflected through metaphors of learning. Lipponen, Hakkarainen and Paavola (2004) distinguish between the acquisition, participation, and knowledge creation metaphor: acquisition focuses on internalisation (i.e., individual knowledge gain), participation stresses interaction (sharing expertise/ distributed expertise), and knowledge creation concentrates on transformation (continuous advancement of shared knowledge). Each metaphor has consequences for how the collaborative process is conceived. The metaphors also limit the degrees of freedom with respect to how the phenomena should be investigated. Key to the interpretation of research outcomes is not only the theory that underlies the study, but also the methodology by which the results were obtained. There are clear guidelines for the development and use of questionnaires and analysis of their data, but requirements for other methodologies, for example content analysis and coding, are less clear cut. Information on the application of a certain methodology (i.e., 'how to' and 'when') is rare in academic research reports. The focus is on research outcomes, and not on specifics as to how these were obtained (most method sections contain rarely sufficient information to repeat the study or a specific analysis). Nevertheless, the corpus of scientific knowledge accumulated in a field of research is shaped (this means also: limited) markedly by the specific methodologies used. This is one of the reasons why methodological debates as a form of collaborative reflection should be a core aspect in scientific discourse in this field of research. Thus far, this is not often the case.

In this special issue 'methodology' is viewed rather broadly, encompassing issues such as: the principled research setting used to investigate (i.e., paradigm), reliability and validity of 
analysis methods and techniques, operationalisation of variables of interest and development and application (including assumptions) of statistical techniques and data display techniques. Analysis methods can be roughly distinguished along the core aspects of a study or a research programme in terms of the research goal, the processes to be studied, data sources, results and interpretation:

- hypothesis testing (theoretical assumptions a priori; prospective) applies quantitative methods, e.g. statistical analyses on Likert-scale or test-scores;

- hypothesis generation (typically a posteriori and data-driven; retrospective) applies qualitative methods, e.g. describing themes that emerged through interviews;

- different processes (i.e., cognitive, social, and motivation), collected or extracted from different data sources, often require different analysis methodologies;

- the method restricts data sources that are considered appropriate for data analysis (i.e., video, documents, interviews, observations, discourse, etc.);

- the method restricts the results that can be derived from the selected data sources;

- the method restricts what can be revealed by and/or inferred from the results extracted with a specific method (generalisation).

We have chosen the word 'restrict' deliberately to emphasise that a chosen methodology does not only lead to a specific view (and analysis) of data, but also simultaneously excludes other possible ways in which the data can be viewed and analysed.

\section{Methodologies used in collaborative learning research}

A central aspect to the analysis of collaborative learning is whether the unique added value of interaction can be measured or inferred from interaction, or that this can only be derived from the individual cognitive residue. There is a distinction with respect to analysis methodologies between theoretical approaches in collaborative learning research. We will briefly discuss the issue through two theoretical approaches, but it should be noted that this list is not intended to 
be exhaustive, but rather to illustrate the different views in the field (see also Stahl, Koschmann, \& Suthers, 2006).

On the one hand there are qualitative, descriptive and interpretative approaches (e.g., Arnseth \& Ludvigsen, 2006; Kumpulainen \& Mutanen, 1999; Roschelle, 1996; Stahl, 2006) focusing on collaboration in practice. These approaches place a strong emphasis on the situated nature of collaboration and the impact of certain situational factors (with a few or as little as possible a priori expectations). On the other hand there are quantitative comparative approaches to study the impact of systematic variations of instruction (e.g., Oortwijn, Boekaerts, Vedder, \& Strijbos, in press; Webb \& Mastergeorge, 2003) on cognitive, social and/ or motivational processes (e.g., knowledge acquisition or help giving) and typically, this is conducted with an interventionist orientation, a priori expectations about instructional variations, and statistical testing.

\section{Beyond mutual ignorance: Minimal description standards, mixed methods, and hybrid methods}

Still, many researchers are inclined to ignore the findings from studies that used 'alien' methodologies. With little or no knowledge about alien methodologies, it is impossible to determine whether a method is actually appropriate to investigate the research question. Moreover, without knowledge on community standards of method application, it is impossible to evaluate the quality of method use. With increasing knowledge about the alien methodologies used - as is the case for many researchers in the field of (computer-supported) collaborative learning - things begin to change. The appropriation of alien methodologies ranges from (1) a demand for minimal description standards for the methodologies in every publication that is directed to the multidisciplinary audience, to the (2) use of mixed methods, and to the (3) fusion of hybrid methodologies, often in cross-perspective research collaborations. 
With respect to coding some minimal description standards have been formulated, for example that an article should state whether the author(s) participated in the process to establish the reliability (De Wever, Schellens, Valcke, \& Van Keer, 2006) and that when reusing a coding scheme a reliability statistic for the original and the current use of the coding scheme should be reported (Strijbos, Martens, Prins, \& Jochems, 2006). Requirements with respect to qualitative descriptive approaches include reporting if and how multiple analysts compared two or more interpretive perspectives (Elliot, Fischer, \& Rennie, 1999).

Current collaborative learning research increasingly applies mixed method strategies. For example, recent approaches combine discourse analysis with coding (e.g., Barron, 2003; Hmelo-Silver, 2003; Weinberger \& Fischer, 2006) and increasingly apply triangulation procedures to integrate results derived from different data sources (Schrire, 2006; Strijbos, Martens, Jochems, \& Broers, 2007).

The appreciation and understanding of a methodology different from the methodology that is central to a researchers' discipline or background may lead to the development of hybrid methodologies: a fusion of quantitative and qualitative research perspectives (Suthers, 2005). Such fusion would involve 'collaborative learning' by the field. By definition it requires that researchers are: (a) willing to study a methodology that is not yet part of their own repertory, (b) willing to look at that methodology unreservedly and unbiased, so they can appreciate it for the type of research questions it can answer and how it could enhance (or be an addition to) their own perspective, and (c) willing to participate in collaborative projects where one of the primary goals is to develop hybrid methods. These requirements call for a stance towards collaborative learning research that does not favour one methodology approach over another, but carefully considers to what extent a specific methodology can answer a specific question within a specific theoretical context.

\section{Current methodological challenges: Overview of the articles in this special issue}


The articles in this special issue provide an overview of methods that form the core of current research efforts. Although they all focus on computer-supported settings, the methodological issues apply to face-to-face (or a blended learning context) as well. The articles identify gaps and how different methods can be sensibly combined, but most importantly they also point to the following five major challenges for collaborative learning research.

(1) The multilevel challenge. One of the toughest challenges in collaborative learning research has to do with the question of how to appropriately grasp and disentangle the effects and dependencies on the individual level, the group level, and sometimes the classroom level. Neglecting the dependencies between individual values can result in an overestimation of statistical significance (Strijbos, Martens, Jochems, \& Broers, 2004). One approach to handle this issue is using aggregated individual level scores to analyse the group level as done by Weinberger, Stegmann and Fischer (2007). Another approach is a multilevel analysis, i.e. a technique that was specifically developed to handle 'nested designs' (e.g., individuals in groups in classrooms), as performed by De Wever, Van Keer, Schellens and Valcke (2007). Still another way to address the dependencies is, to separate the individual and group level perspective in the analysis and later triangulate their results during the interpretation phase (Arvaja, Salovaara, Häkkinen, \& Järvelä, 2007).

(2) The convergence/divergence challenge. Most theoretical approaches to collaborative learning assume a mutual influence of learning partners in one group. Some of them specify convergence or divergence as basic concepts. Challenges that remain: a) how to assess these concepts, b) how to determine whether the contributions by two learners have become more similar over time, and c) how to measure shared knowledge as an outcome of a convergent process? De Wever et al. (2007) and Beers, Boshuizen, Kirschner and Gijselaers (2007), as well as Weinberger, Stegmann, and Fischer (2007) address this challenge in their articles. Prototypically, Weinberger et al. (2007) show ways to measure knowledge convergence and 
divergence in the collaborative process in terms of the use of increasingly similar or dissimilar content in contributions to a discussion, as well as increasingly similar or dissimilar ways to discuss that content. With respect to the outcomes they show how knowledge tests scores can be used to identify shared and unshared knowledge.

(3) The segmentation and coding challenge. As coding and content analysis are frequently applied in (computer-supported) collaborative learning research, it should be no surprise that three articles address methodological challenges associated with the technique. Strijbos and Stahl (2007) discuss three issues that emerged when developing a coding scheme to analyse small group chat communication: handling unit fragmentation, reconstruction of the response structure, and reliability over-estimation in a case of missing values. Zemel, Xhafa and Cakir (2007) show the applicability of a user-defined unit of analysis when coding small group chat communication. The article by Beers et al. (2007) addresses another pivotal coding issue: the tensions between achieving reliability without compromising validity, such as how to define codes and rules for applying these codes.

(4) The fusion of hybrid methods challenge. Zemel et al. (2007) illustrate the feasibility of hybrid methods by combining two often applied, yet disparate, methods: coding for statistical analyses and conversation analysis. They also point out that it requires a deep understanding of both methods. The development of hybrid methods is not a task for a 'lone researcher', but rather for a research group or even several research groups in collaborations. Furthermore, these hybrid methods need to be well documented in such a way that future researchers can apply them, without the in-depth "fusion" processes of the methodology development phase.

(5) The situational challenge. There is hardly any approach to collaborative learning not emphasizing on the crucial role of the context. The context, however, is nothing that is easily included when it comes to measuring. In line with the demand by Naidu and Järvelä (2006) for a contextual perspective in the analysis of collaborative learning, Arvaja et al. (2007) 
discuss a method to determine the impact of the context of the collaborative setting on the collaborative process and on knowledge construction. They present a framework to incorporate the contextual influences in the analysis of collaborative knowledge construction.

In their commentary Hmelo-Silver and Bromme (2007) provide an insightful discussion of the affordances and limitations of the articles.

It is our hope that the articles in this special issue provide starting points for the establishment of minimal description standards and guidelines, in terms of the type of information and level of detail needed to ensure that a collaborative learning researcher will be able to both understand and appreciate methods that originated in another discipline. It would be a success of this special issue, if it could stimulate and encourage applications of mixed method designs or even the co-developments of hybrid methods.

\section{References}

Arnseth, H. C., \& Ludvigsen, S. (2006). Approaching institutional contexts: Systemic versus dialogic research. International Journal of Computer Supported Collaborative Learning, $1,167-185$.

Arvaja, M., Salovaara, H., Häkkinen, P. \& Järvelä, S. (2007). Combining individual and group-level perspectives for studying collaborative knowledge construction in context. Learning \& Instruction, 17, 448-459.

Barron, B. (2003). When smart groups fail. The Journal of the Learning Sciences, 12, $307-$ 359.

Beers, P. J., Boshuizen, H. P. A, Kirschner P. A., \& Gijselaers, W. H. (2007). The analysis of negotiation of common ground in CSCL. Learning \& Instruction, 17, 427-435.

De Wever, B., Schellens, T., Valcke, M., \& Van Keer, H. (2006). Content analysis schemes to analyze transcripts of online asynchronous discussion groups: A review. Computers \& Education, 46, 6-28. 
De Wever, B, Van Keer, H., Schellens, T., \& Valcke, M. (2007). Applying multilevel modelling to content analysis data: Methodological issues in the study of role assignment in asynchronous discussion groups. Learning \& Instruction, 17, 436-447.

Elliot, R., Fischer, C. T., \& Rennie, D. L. (1999). Evolving guidelines for publication of qualitative research studies in psychology and related fields. British Journal of Clinical Psychology, 38, 215-229.

Hmelo-Silver, C. E. (2003). Analyzing collaborative knowledge construction: Multiple methods for integrated understanding. Computers \& Education, 41, 397-420.

Hmelo-Silver, C. E., \& Bromme, R. (2007). Coding discussions and discussing coding: Research on collaborative learning in computer-supported environments. Learning \& Instruction, 17, 460-464.

Kumpulainen, K., \& Mutanen, M. (1999). The situated dynamics of peer group interaction: An introduction to an analytic framework. Learning \& Instruction, 9, 449-473.

Lipponen, L., Hakkarainen, K., \& Paavola, S. (2004). Practices and orientations of CSCL. In P. Dillenbourg (Series Ed.) \& J. W. Strijbos, P. A. Kirschner \& R. L. Martens (Vol. Eds.), What we know about CSCL: And implementing it in higher education (pp. 31-50). Boston, MA: Kluwer Academic Publishers.

Naidu, S., \& Järvelä, S. (2006). Analyzing CMC content for what? Computers \& Education, 46, 96-103.

Oortwijn, M. B., Boekaerts, M., Vedder, P., \& Strijbos, J. W. (in press). Helping behaviour during cooperative learning and learning gains: The role of the teacher and of pupils' prior knowledge and ethnic background. Learning \& Instruction.

Roschelle, J. (1996). Learning by collaborating: Convergent conceptual change. In T. Koschmann (Ed.), CSCL: Theory and practice of an emerging paradigm (pp. 209-248). Mahwah, NJ: Lawrence Erlbaum Associates. 
Schrire, S. (2006). Knowledge building in asynchronous discussion groups: Going beyond quantitative analysis. Computers \& Education, 46, 49-70.

Stahl, G. (2006). Group cognition: Computer support for building collaborative knowledge. Cambridge, MA: MIT Press.

Stahl, G., Koschmann, T., \& Suthers, D. (2006). Computer-supported collaborative learning: A historical perspective. In R. K. Sawyer (Ed.), Cambridge handbook of the learning sciences (pp. 406-427): Cambridge, UK: Cambridge University Press.

Strijbos, J. W., Martens, R. L., Jochems, W. M. G., \& Broers, N. J. (2004). The effect of functional roles on perceived group efficiency: Using multilevel modeling and content analysis to investigate computer-supported collaboration in small groups. Small Group Research, 35, 195-229.

Strijbos, J. W., Martens, R. L., Jochems, W. M. G., \& Broers, N. J. (2007). The effect of functional roles on perceived group efficiency during computer-supported collaborative learning: A matter of triangulation. Computers in Human Behavior, 23, 353-380.

Strijbos, J. W., Martens, R. L., Prins, F. J., \& Jochems, W. M. G. (2006). Content analysis: What are they talking about? Computers \& Education, 46, 29-48.

Strijbos, J. W., \& Stahl, G. (2007). Methodological issues in developing a multi-dimensional coding procedure for small group chat communication. Learning \& Instruction, 17, 394404.

Suthers, D. (2005). Technology affordances for intersubjective learning, and how they may be exploited. In P. Dillenbourg (Series Ed.) \& R. Bromme, F. W. Hesse \& H. Spada (Vol. Eds.), Biases and barriers in computer-mediated knowledge communication: And how they may be overcome (pp. 295-319). Boston, MA: Kluwer Academic Publishers. 
Webb, N. M., \& Mastergeorge, A. M. (2003). The development of students' helping behaviour and learning in peer-directed small groups. Cognition \& Instruction, 21, 361428.

Weinberger, A., \& Fischer, F. (2006). A framework to analyze argumentative knowledge construction in computer-supported collaborative learning. Computers \& Education, 46 , $71-95$.

Weinberger, A., Stegmann, K., \& Fischer, F. (2007). Knowledge convergence in collaborative learning: Concepts and assessment. Learning \& Instruction, 17, 416-426.

Zemel, A., Xhafa, F., \& Cakir, M. (2007). What's in the mix? Combining coding and conversation analysis to investigate chat-based problem-solving. Learning \& Instruction, $17,405-415$ 